\title{
ALTERAÇÃO DE SABOR E AROMA EM TOMATES CAUSADA POR IMPACTO
}

\author{
Celso Luiz Moretti ${ }^{1,3 *}$; Steven Alonzo Sargent ${ }^{2}$ \\ ${ }^{1}$ Embrapa Hortaliças, Rod. BR 060, km 09, C.P. 218 - CEP: 70359-970 - Brasília, DF. \\ ${ }^{2}$ Horticultural Sciences Department - IFAS - University of Florida, 32611 - Gainesville, Florida, EUA. \\ ${ }^{3}$ Bolsista CNPq. \\ *Autor correspondente <celso@cnph.embrapa.br>
}

\begin{abstract}
RESUMO: Tomates (Lycopersicon esculentum Mill), 'Solar Set' e 'Agriset-743', foram colhidos no estádio verde-maduro ( $100 \%$ da superfície com coloração verde) e tratados com $100 \mu \mathrm{L} \mathrm{L}^{-1}$ de etileno gasoso a $20^{\circ} \mathrm{C}$. Quando atingiram o estádio verde-rosado (menos do que $10 \%$ da superfície do fruto possui coloração vermelha ou amarelo-esverdeada), os frutos foram divididos em dois lotes. Um lote sofreu quedas de $40 \mathrm{~cm}$ de altura sobre uma superfície plana, rígida e lisa. Os frutos deste lote foram armazenados com os frutos-controle (que não sofreram dano mecânico) a $20^{\circ} \mathrm{C}$ e $85-95 \%$ de umidade relativa. No estádio vermelho, os frutos inteiros foram homogeneizados e um teste de análise sensorial foi imediatamente conduzido. Os painelistas foram capazes de distinguir entre frutos com desordem fisiológica causada por impacto e frutos não-injuriados, indicando que esta injúria alterou de maneira significativa o sabor e 0 aroma dos tomates analisados.

Palavras-chave: Lycopersicon esculentum, análise sensorial, injúria mecânica, pós-colheita
\end{abstract}

\section{FLAVOR ALTERATION IN TOMATO FRUITS DUE TO INTERNAL BRUISING}

\begin{abstract}
Tomato (Lycopersicon esculentum Mill.) fruits, 'Solar Set' and 'Agriset - 743', were harvested at the mature-green stage of development and treated with $100 \mu \mathrm{L} \mathrm{L}^{-1}$ ethylene at $20^{\circ} \mathrm{C}$. At the breaker stage, fruits were dropped from $40 \mathrm{~cm}$ height to induce internal bruising and stored along with undropped fruits at $20^{\circ} \mathrm{C}$ and $85-95 \% \mathrm{RH}$. At the table-ripe stage, whole fruits were chopped in a food processor and a sensory analysis test was immediately performed. The experimental design employed was a completely randomized blocks scheme arranged with 22 panelists (blocks), 3 treatments (unbruised sample; bruised sample 1 and bruised sample 2) and 4 replicates (ten fruits each). Data were subjected to analysis of variance and differences among treatments were determined by the $F$ test $(P=0.05)$. Panelists were able to distinguish between bruised and unbruised fruits which indicated that internal bruising caused by impact altered tomato flavor.

Key words: Lycopersicon esculentum, sensory analysis, mechanical damage, post-harvest
\end{abstract}

\section{INTRODUÇÃO}

Sabor, aroma e textura são características que estão intrinsecamente relacionadas com a qualidade de tomates frescos (Baldwin et al., 1991). Vários compostos químicos estão envolvidos na determinação do sabor e aroma característicos de tomates: ácidos orgânicos (principalmente ácido cítrico), açúcares redutores, aminoácidos livres e compostos voláteis (Petró-Turza, 1987). Injúrias mecânicas devidos à impactos, compressão, vibração, cortes e rachaduras estão relacionadas com alterações fisiológicas, metabólicas, de aroma e sabor e de qualidade de diferentes produtos hortícolas tais como maçãs, pepinos, batatas e tomates. Miller et al. (1987) observaram aumento na atividade das enzimas relacionadas com a degradação de parede celular no pericarpo de pepinos submetidos à injúria mecânica de impacto.

Em tomates, a ocorrência de impactos pode causar o aparecimento de desordem fisiológica, que altera o curso normal de amadurecimento destes frutos (Halsey, 1955). Tomates com esta desordem possuem o tecido locular em colapso, desorganizado, com coloração verde- amarelada, de aspecto turvo e, em casos mais severos, o tecido locular apresenta-se com extensa perda de água (Hatton \& Reeder, 1963). A incidência e a severidade da desordem fisiológica dependem da energia de impacto, da cultivar em estudo, do número de impactos e do estádio de amadurecimento. Ela é cumulativa durante as práticas de manuseio pós-colheita (McColloch, 1962; Sargent et al., 1992).

Adicionalmente aos sintomas visuais, as injúrias mecânicas podem causar alterações metabólicas em diversos produtos hortícolas. MacLeod et al. (1976) concluíram que ao aumentar-se o número de impactos de $40 \mathrm{~cm}$ de altura, aumentou-se a evolução de gás carbônico e etileno em tomates. Egan (1982), estudando tomates, observou que impactos reduziram a firmeza de 1,6 para $1,3 \mathrm{kgf} \mathrm{cm}^{-2}$. Por outro lado, Silva \& Calbo (1992) observaram que tomates submetidos à compressão apresentaram redução na evolução de gás carbônico e atraso no amadurecimento. Geerts et al. (1994) observaram que a atividade da lipoxigenase foi alterada em tubérculos de batata após a ocorrência de injúrias mecânicas. 
Embora exista uma considerável quantidade de trabalhos abordando os efeitos de injúrias mecânicas sobre a fisiologia, metabolismo, aparência e qualidade de tomates com desordem fisiológica causada por impacto, há uma lacuna na literatura no que diz respeito ao estudo das alterações de aroma e sabor e aceitação de frutos injuriados por parte do consumidor.

O objetivo do presente trabalho foi avaliar alterações de sabor e aroma de frutos de tomate com desordem fisiológica causada por impacto.

\section{MATERIAL E MÉTODOS}

Material Vegetal: Tomates (Lycopersicon esculentum Mill), 'Solar Set' e 'Agriset-743', no estádio verde-maduro $(100 \%$ da superfície do fruto possui coloração verde) (USDA, 1976), foram colhidos em campos comerciais em Bradenton (Flórida, EUA) e na unidade de horticultura da Universidade da Flórida, Gainesville, EUA. Após a colheita, os frutos foram colocados em bandejas de isopor, similares às usadas para transporte de ovos, e transportados no mesmo dia para o laboratório de pós-colheita da Universidade da Flórida (EUA).

Aplicação de etileno e injúria mecânica de impacto: Os frutos foram selecionados de acordo com tamanho (frutos médios com 63 a $72 \mathrm{~mm}$ de diâmetro) e massa $(140 \pm 10 \mathrm{~g})$, e tratados com etileno gasoso $(100 \mu \mathrm{L}$ $\mathrm{L}^{-1}$ ) em um sistema de fluxo aberto (fluxo $=50 \mathrm{~mL} \mathrm{~s}^{-1}$ ) a $20^{\circ} \mathrm{C}$ e $85-95 \%$ de umidade relativa. Ao atingirem o estádio verde-rosado (menos de $10 \%$ da superfície do fruto possui coloração avermelhada ou amarelo - esverdeada) (USDA, 1976), os frutos foram divididos em dois lotes de 60 frutos cada, sendo um deles submetido à injúria mecânica e outro utilizado como controle. Os frutos foram individualmente seguros por um sistema à vácuo (com o intuito de evitar a rotação do fruto durante a queda) e submetidos a uma queda de $40 \mathrm{~cm}$ de altura sobre uma superfície plana, rígida e lisa. Cada fruto sofreu dois impactos, um sobre cada um dos pontos eqüidistantes de uma linha equatorial imaginária, tentando-se evitar que o impacto atingisse a parede locular que separa dois lóculos adjacentes. Após o impacto, os frutos com injúria mecânica e os nãoinjuriados foram armazenados a $20^{\circ} \mathrm{C}$ e $85-90 \%$ de umidade relativa até atingirem a maturidade comercial para os padrões de firmeza do mercado americano. Este padrão é determinado quando tomates vermelhos $(100 \%$ da superfície do fruto possui coloração vermelha) (USDA, 1976) são colocados sobre uma superfície côncava de borracha e submetidos por 5 segundos a uma força estática de 9,8 $\mathrm{N}$ aplicada sobre a região equatorial através de uma ponta metálica convexa de $11 \mathrm{~mm}$ de diâmetro. O padrão é determinado quando os frutos nas condições acima apresentam uma deformação maior ou igual a 3 $\mathrm{mm}$. A maturidade comercial foi determinada neste experimento utilizando-se um medidor de firmeza do tipo Cornell (Hamson, 1952), adaptado por Gull et al. (1980).
Análise sensorial: No estádio vermelho, tomates inteiros foram homogeneizados em um processador caseiro por 30 segundos e foram submetidos a um teste de diferença do controle (Aust et al., 1985). O homogenato foi colocado em 4 copos opacos: um copo continha a amostra não-injuriada e foi identificada como controle. Os três copos remanescentes receberam números aleatórios de 3 dígitos e consistiam de outra amostra contendo homogenato de frutos não injuriados ("controle escondido") e duas amostras de homogenato de frutos com desordem fisiológica causada por impacto (amostras injuriadas $1 \mathrm{e}$ 2). As amostras foram oferecidas a um painel de análise sensorial composto de 22 membros não-treinados e foi pedido aos painelistas que primeiramente provassem 0 copo identificado como controle e depois os outros três identificados com números, sendo que para efeitos estatísticos, cada painelista provou doze amostras, três em cada uma das 4 seções. O "controle escondido" foi apenas utilizado como um padrão através do qual foram comparados os demais tratamentos. O sabor e o aroma dos três copos numerados aleatoriamente foram comparados com o controle inicialmente amostrado e classificados de acordo com uma escala comparativa variando de 1 (nenhuma diferença) a 12 (extremamente diferente).

Análise estatística: As análises foram feitas para cada variedade de tomate estudada utilizando-se delineamento de blocos inteiramente casualizados, com 22 painelistas como blocos e três tratamentos (frutos não injuriados, frutos injuriados - amostra 1 e frutos injuriados - amostra 2) e 4 repetições (10 frutos por repetição), Os resultados foram submetidos à análise de variância usando-se o teste $\mathrm{F}$ e as médias foram separadas pelo teste de Tukey, a $5 \%$.

\section{RESULTADOS E DISCUSSÃO}

O controle escondido foi classificado com notas 2,2 e 2,1 para 'Solar Set' (Figura 1) e 'Agriset-743' (Figura 2), respectivamente, enquanto as amostras com desordem fisiológica causada por impacto (amostra injuriada $1 \mathrm{e}$ amostra injuriada 2) foram classificadas com valores significativamente maiores, sendo 6,40 e 6,10, respectivamente, para 'Solar Set' (Figura 1) e 5,88 e 5,83, respectivamente, para 'Agriset-743' (Figura 2). Alguns painelistas comentaram que as amostras injuriadas apresentavam-se com sabor "aguado" ou insípido quando comparadas com o controle.

Vários trabalhos têm demonstrado que tomates com desordem fisiológica causada por impacto apresentam alterações significativas em acidez titulável, vitamina $C$ total, atividade enzimática, carotenóides totais, consistência (Moretti et al., 1998) e na concentração de compostos voláteis chaves para a determinação do sabor e aroma característicos do fruto (Moretti et al., 1997). Estas mudanças podem ter sido as responsáveis pelas diferenças observadas pelos painelistas neste 


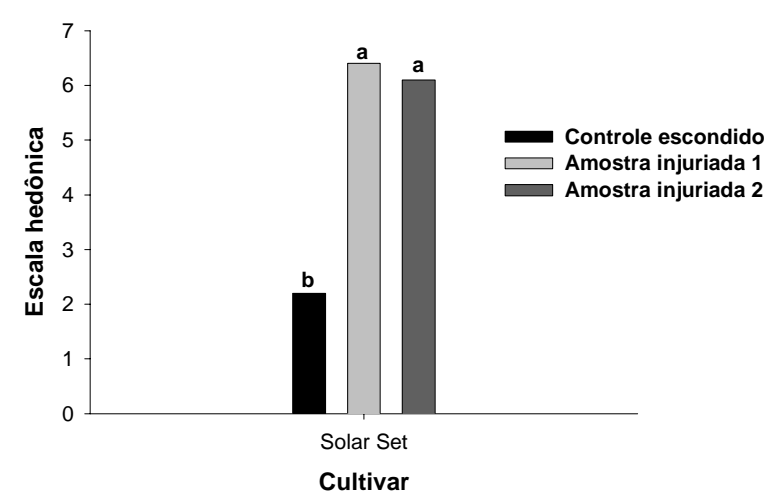

Figura 1 - Médias atribuídas às amostras injuriadas (amostra injuriada $1 \square$ e amostra injuriada $2 \square$ ) e não-injuriadas (controle escondido $\square$ ) de tomates maduros 'Solar Set' utilizando-se o teste de diferença do controle (Escala hedônica de valores: 1 = sem diferença; 12 = extremamente diferente). (Médias identificadas com mesma letra não diferem significativamente pelo teste de Tukey, a $5 \%$ ).

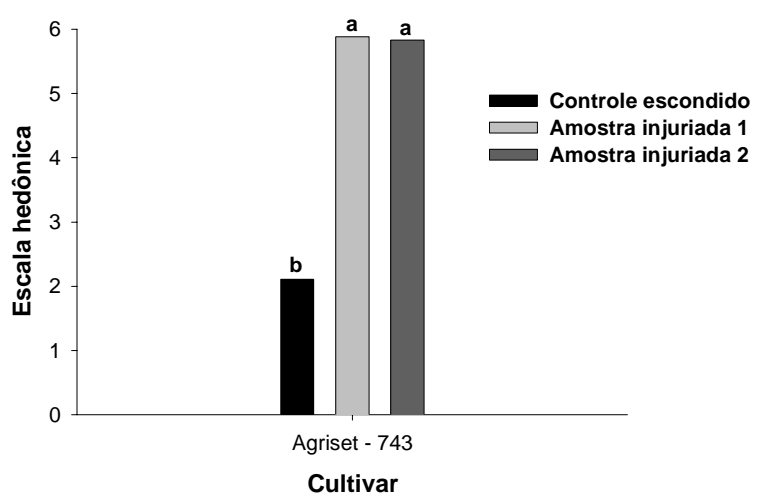

Figura 2 - Médias atribuídas às amostras injuriadas (amostra injuriada $1 \square$ e amostra injuriada $2 \square$ ) e não-injuriadas (controle escondido $\square$ ) de tomates maduros 'Agriset 743' utilizando-se o teste de diferença do controle (Escala hedônica de valores: 1 = sem diferença; $12=$ extremamente diferente). (Médias identificadas com mesma letra não diferem significativamente pelo teste de Tukey, a $5 \%$ ).

experimento. Moretti et al. (1998) determinaram que tecidos com desordem fisiológica causada por impacto possuíam teores de ácidos orgânicos e vitamina $C$ total significativamente menores do que os de frutos nãoinjuriados, e que o tecido locular injuriado apresentava-se com maior consistência do que o tecido proveniente de tomates amadurecidos normalmente. Considerando-se que o tecido locular foi o mais atingido pela desordem fisiológica causada por impacto (Moretti et al., 1997; Moretti et al., 1998) e que seus componentes são percebidos primeiramente pelos receptores de sabor localizados na cavidade bucal (Stevens, 1977), sugere-se que elevações na consistência do tecido locular de tomates possa ser um fator determinante no aroma e sabor.

A percepção de sabor e aroma alterados, em adição às mudanças no conteúdo de ácidos orgânicos, vitaminas e consistência, pode ser devida à alterações na rota metabólica de compostos voláteis chaves para a determinação de aroma e sabor característico de tomates, como cis-3-hexenal, cis-3-hexenol e 6-metil-5-hepteno-2ona (Petró-Turza, 1987). Compostos voláteis como $\beta$ ionona e 6-metil-5-hepteno-2-ona são derivados de carotenóides de cadeia aberta e cíclica, respectivamente (Buttery \& Ling, 1993). Moretti et al. (1998) observaram que o tecido locular de tomates injuriados possuía conteúdo de carotenóides totais significativamente menor do que o de frutos não-injuriados e Moretti et al. (1997) determinaram que 6-metil-5-hepteno-2-ona, um composto que suspeita-se ser um subproduto da degradação de pigmentos carotenóides (Petró-Turza, 1987), foi significativamente reduzido em tecido com desordem fisiológica causada por impacto.

\section{CONCLUSÃO}

A desordem fisiológica causada por impacto altera o sabor e o aroma de tomates, reduzindo de maneira potencial a aceitação deste produto.

\section{REFERÊNCIAS BIBLIOGRÁFICAS}

AUST, L.B.; GACULA, M.C.; BEARD Jr., S.A.; WASHAM R.W. Degree of difference test method in sensory evaluation of heterogeneous product types. Journal of Food Science, v.50, p.511-513, 1985.

BALDWIN, E.A.; NISPEROS-CARRIEDO; M.O.; MOSHONAS, M.G. Quantitative analysis of flavor and other volatiles and for certain constituents of two tomato cultivars during ripening. Journal of the American Society for Horticultural Science, v.116, p.265-269, 1991.

BUTTERY, R.G.; LING, L.C. Volatile compounds of tomato fruit and plant parts: relationship and biogenesis. In: TERANISHI, R.; BUTTERY, R.G.; SUGISAWA, A.R. (Ed.) Bioactive volatile compounds from plants. Washington: American Chemical Society, 1993. p.23-34. (Symposium Series, 525).

EGAN, S. Methods of handling affects tomato fruit quality. Farm and Food Research, v.13, p.72-74, 1982.

GEERTES, A.; FELTKAMP, D.; ROSAHL, S. Expression of lypoxigenase in wounded tubers of Solanum tuberosum L. Plant Physiology, v.105, p.269-277, 1994.

GULL, D.; CARTAGENA, D.; FRENCH, E.C. Análisis de calidad de tomato para lograr um mejor producto. Cochabamba: IBTA; PRODES; UFLA, 1980. 20p.

HALSEY, L.H. Preliminary studies of bruising of 'turning' and 'pink' tomatoes caused by handling practices. Proceedings of the Florida State Horticultural Society, v.68, p.240-243, 1955.

HAMSON, A.R. Measuring firmness of tomatoes in a breeding program. Proceedings of the American Society for Horticultural Science, v.60, p.425-433, 1952.

HATTON, T.T.; REEDER, W.F. Effect of field and packinghouse handling on bruising of Florida tomatoes. Proceedings of the Florida State Horticultural Society, v.76, p.301-304, 1963.

MACLEOD, R.F.; KADER, A.A.; MORRIS, L.L. Stimulation of ethylene and $\mathrm{CO}_{2}$ production of mature-green tomatoes by impact bruising. HortScience, v.11, p.604-606, 1976.

MCCOLLOCH, L.P. Bruising injury of tomatoes. Washington: Proceedings. Washington: USDA, 1962. 35p. (Marketing Research Report, 513). 
MILLER, A.R.; DALMASSO, J.P.; KRETCHMAN, D.W. Mechanical stress, storage time and temperature influence cell wall degrading enzymes, firmness and ethylene production by cucumbers. Journal of the American Society for Horticultural Science, v.112, p.666-671, 1987.

MORETTI, C.L.; SARGENT, S.A.; BALDWIN, E.; HUBER, D.J.; PUSCHMANN, R. Pericarp, locule and placental tissue volatile profiles are altered in tomato fruit with internal bruising. In: CONGRESSO BRASILEIRO DE FISIOLOGIA VEGETAL, 6., Belém, 1997. Resumos. Belém, 1997. v.1, p.216.

MORETTI, C.L.; SARGENT, S.A.; HUBER, D.J.; CALBO, A.G..; PUSCHMANN, R. Chemical composition and physical properties of pericarp, locule and placental tissues of tomatoes with internal bruising. Journal of the American Society for Horticultural Science, v.123, p.656-660, 1998.

PETRÓ-TURZA, M. Flavor of tomato and tomato products. Food Reviews International, v.2, p.309-351, 1987.
SARGENT, S.A.; BRECHT, J.K.; ZOELLNER, J.J. Sensitivity of tomatoes at mature green and breaker ripeness stages to internal bruising. Journal of the American Society for Horticultural Science, v.117, p.119-123, 1992.

SILVA, J.L.O.; CALBO, A.G. An apparatus to study compression stress in fruits and vegetables. Pesquisa Agropecuária Brasileira, v.27, p.737-742, 1992.

STEVENS, M.A. Inheritance of viscosity potential in tomato. Journal of the American Society for Horticultural Science, v.101, p.152-155, 1977.

USDA. United States Standard for grades of fresh market tomatoes. Washington: USDA, Agricultural Marketing Service, 1976.

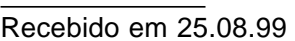

